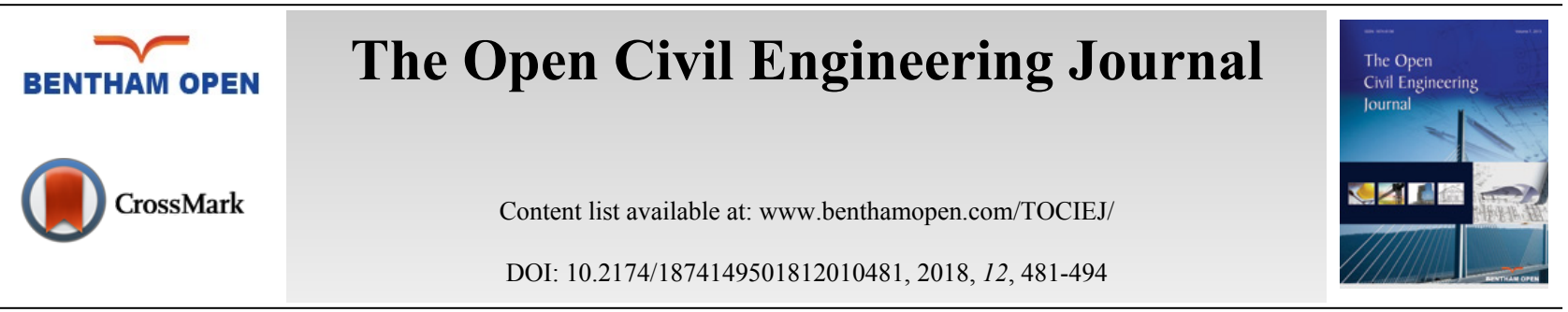

RESEARCH ARTICLE

\title{
Influence of Member Length Imperfection on the Capacity of Spatial Structures
}

\author{
Mehrdad Gordini, Mohammad R. Habibi ${ }^{*}$, Mohammad H. Tavana, Moslem Amiri and Mehrzad T. \\ Roudsari
}

Department of Civil Engineering, Kermanshah Branch, Islamic Azad University, Kermanshah, Iran

Received: July 20, 2018

Revised: November 2, 2018

Accepted: November 15, 2018

\section{Abstract:}

\section{Introduction:}

Load bearing capacity of Double Layer Grid Spatial Trusses (DLGST) majorly depend on the structures' imperfections. It is important to analyze the systems with consideration of the influences of uncertainties to ensure the safety of DLGST.

\section{Methods:}

The variation of imperfect members' positions and initial size of length imperfections (being longer or shorter than the ideal size) were selected as the parameters of the current research. Member length imperfections for both long and short members were randomly taken into account according to the randomly generated numbers. These random numbers were generated using a normal distribution.

\section{Results and Conclusion:}

The effect of imperfection is investigated by repeating the analyses simulations on structures with a stochastic dispersion of the imperfect member position and initial length imperfection. It has been demonstrated that the length imperfections might significantly decrease safety of the structure and also shown that the position of imperfect members has effect on the structural performance.

Keywords: Space frame systems, Imperfections, Safety, Steel structures, Double-layer grid spatial truss, Spatial structures.

\section{INTRODUCTION}

The development of space structures has actually played a major role in engineering design, allowing architects and engineers to push the boundaries to design even bigger and more exciting structures. A Double-Layer Grid Spatial Truss (DLGST) is a popular form of space frame which has received much attention in the past few decades due to its efficient structural system which can cover large column free area. Applications of double-layer space structure are numerous and include the notorious Hartford Coliseum space roof truss in Connecticut USA. However, the catastrophic failure of this particular space roof truss in 1978 resulted in extensive research on the progressive failure of space trusses [1 - 3]. Obviously, the aftermath of any building collapse is disastrous and very unfortunate, however, the failure of the Coliseum roof along with other failures in more conventional structures has led structural engineers to realize the importance of progressive collapse in buildings [4].

However, although past codes of practice provide design procedures for very long bridges and vulnerable structures, recent codes still lack general applicability to double-layer grids. DLGST are in general highly efficient structures and they have wide applications in civil engineering. Because of their large internal degree of static indeterminacy, DLGST

\footnotetext{
" Address correspondence to this author at the Department of Civil Engineering, Kermanshah Branch, Islamic Azad University, Kermanshah, Iran, Tel: 00989187393590; Fax: 0098-833-8432879; E-mail: m.r.habibi@iauksh.ac.ir.
} 
are often mistakenly assumed to have sufficient redundancy such that the loss of one member would cause force redistribution that can be accommodated by remaining structures. However, results of several experimental and parametric studies show that progressive collapse could occur following the loss of one of the several potentially critical members when the structures are subject to full service loading [5 - 8]. An example of this vulnerability is what happened to the crest shaped football stadium built in Terengganu, Malaysia which had a double-layer space roof truss. The stadium collapsed one year after its completion on 2nd June 2009. It was reported that the stadium collapsed just as the main contractor was about to replace a number of critical buckled members. The behavior of double layer space structure is dependent on their axial load- axial displacement response of compressive members. The lack of fit in the members of double layer space structures is the most common form of imperfection. Consequently, this type of imperfection in the compressive members will change the behavior of these structures.

Extensive experimental evidence indicates that double-layer grids are highly sensitive to the effects of random imperfections, owing to their high degree of static indeterminacy and stiffness. The DLGSTs are vulnerable to member's imperfections, due to their manufacturing difficulties. Load bearing capacity of these structures often falls between $25 \%$ and $40 \%$ below the elastic limit $[9,10]$. The existence of imperfect members in DLGST is almost unavoidable in practice. These imperfections affect the load carrying capacity of DLGST. The high degree of indeterminacy plays no part in controlling the progressive failure and causes adverse effects by introducing the residual stresses due to any uncertainties in the form of initial geometric imperfections, member end eccentricities, joint flexibility, imperfect boundary conditions and human error. El-Sheikh studied on the effect of member imperfections on capacity of space trusses. At the end of the study, it was concluded that only $0.1 \%$ imperfection in the truss member leads to a decrease in the truss strength capacity up to $31.6 \%$, in a critical compression member [11 - 13].

The studies conducted so far have shown that space frame systems are extremely sensitive to geometric deficiencies (bent components, the length of the components not being an ideal size, etc.) $[14,15]$. The deficiencies occurring in the lengths of the components of the space frame systems (the length of the components being longer or shorter than the ideal size) might be appeared due to human-based reasons like manual cuts, tolerance sensitivity-based in CNC cuttings, and/or due to changes in temperature. It is not possible to construct a space frame system that is free from geometric deficiencies in practice [16]. The designer must take these imperfections into consideration during the design process, since it is very important to ensure the building safety.

Several researches were carried out on the early failure of the space structures. The studies showed that space trusses are highly sensitive to the uncertainties and demonstrated that the high structural redundancy in space structures makes them more sensitive and becomes one of the causes for the premature and progressive failure [17 - 24].

Existence of initial imperfections in the assembly or manufacturing process of DLGST is unavoidable. The important question is how the structure would behave after the imperfections in the members. In this study, the effects of length imperfection of some members of DLGST on the Capacity of DLGST have been investigated. A special computer program which considers length imperfections is developed to perform comprehensive analyses of the DLGSTs. The variation of imperfect members positions, and initial size of length imperfections were selected as the parameters for component uncertainties. Theoretical background of the approach to solve truss system with imperfections is explained in detail.

\section{METHODS \& MATERIALS}

\subsection{Finite Element Modeling}

A computer program that can perform analyses by considering the member length imperfections $(\Delta \mathrm{L}$-being longer or shorter than the ideal lengths) has been developed. The program performs analyses by taking the maximum length imperfection size $(\Delta \mathrm{L})$ of chosen truss member, and the number of the imperfect truss member into consideration. Imperfections are randomly distributed among the members of trusses by the program. Before the analysis, the program marks the truss members which are assigned length imperfections with different colors depending on them being short or long. Similarly, after the analysis, the program calculates the number of the members which exceed limit capacity ratio. The program colors the places of the deficient truss member which exceeds the allowable stresses.

Fig. (1) is used to incorporate length imperfection into the truss analysis. Perfect truss member is supposed to be between points $\mathrm{i}$ and $\mathrm{j}$; and its original length is supposed be Lk. If the length of the element is fabricated too short, tensile force would act on the element and element would be stretched to new position (iT, jT) to fit into the structure. Conversely, if the length is a little bit longer, then compression force would be acting on the element to fit into the 
given structure. If compatibility is written for a situation given in Fig. (1), the Eq. (1) is obtained as shown below:

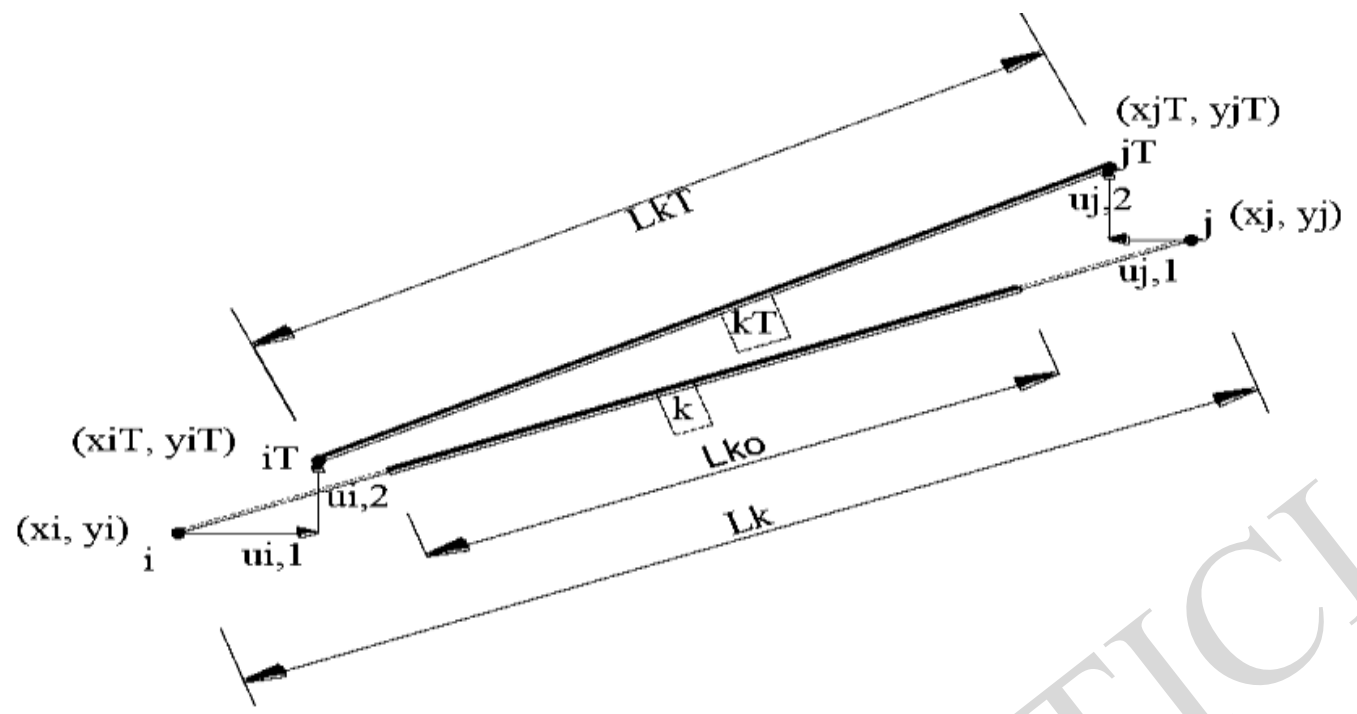

Fig. (1). Demonstration of length imperfection of a truss member.

$$
\begin{gathered}
\sqrt{ }(\mathrm{xjT}-\mathrm{xiT})^{2}+(\mathrm{yj} \mathrm{T}-\mathrm{yiT})^{2}+(\mathrm{zjT}-\mathrm{ziT})^{2}=(\mathrm{Nko} * \mathrm{Lko} / \mathrm{EAk})+\mathrm{Lko} \\
\mathrm{XiT}=\mathrm{xi}+\mathrm{ui}, 1 \\
\mathrm{XjT}=\mathrm{xj}+\mathrm{uj}, 1 \\
\mathrm{YiT}=\mathrm{yi}+\mathrm{ui}, 2 \\
\mathrm{YjT}=\mathrm{yj}+\mathrm{uj}, 2 \square
\end{gathered}
$$

Where the definition of xiT, xjT, yiT, yjT are given in Eq. (2 to 5).

Applying equilibrium equations at each joint, it would get enough equations to solve the unknowns (ui, 1, ui,2, uj,1, uj,2, and Nko). Stiffness matrix of a truss element with length imperfection can be defined as follows: Eq. (6).

$k_{k}$

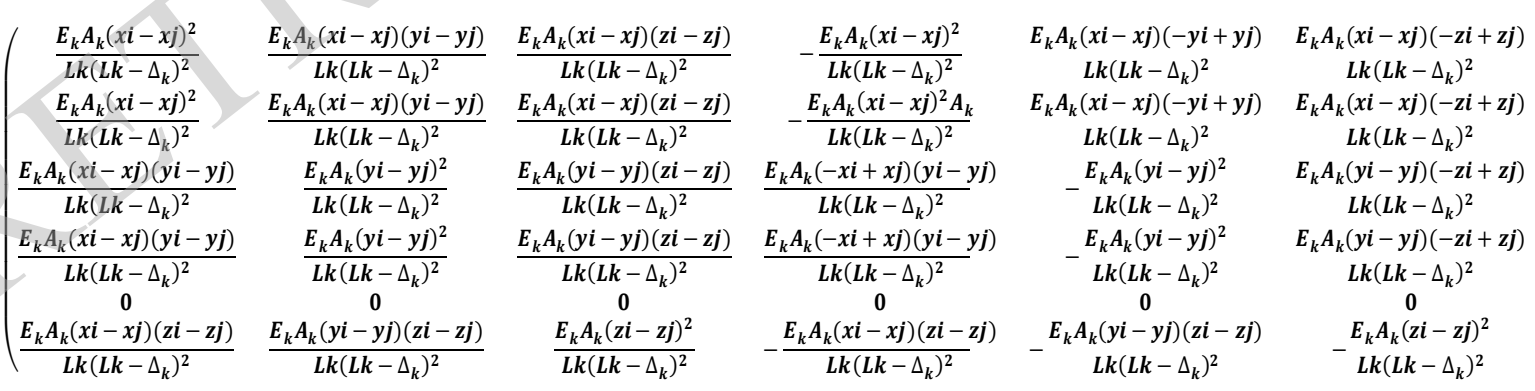

\subsubsection{Numerical simulation Verification}

To verify the computer program which considers length imperfection prepared for this study, an example shown in Fig. (2) is used. A closed form of analytical solution of this problem is known. The system consisting of two bars with $2000 \mathrm{~cm}$ and $500 \mathrm{~cm}$ lengths between the two structural bearings have been taken into consideration in Fig. (2). The cross-sectional areas of the bars are accepted as $300 \mathrm{~mm}^{2}$ and $200 \mathrm{~mm}^{2}$, respectively. The elastic modulus is accepted as $200 \mathrm{GPa}$. It is assumed that the thin bar is fabricated with the length of $375 \mathrm{~mm}$, which is too short to exact fit. It is assumed that structural members are forced to fit to support position as in the project. 


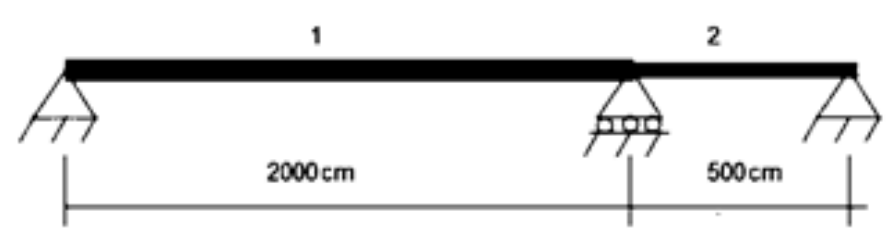

Fig. (2). Double-component system with defects in lengths.

$$
\begin{gathered}
\Delta \mathrm{gap}=\Delta 1+\Delta 2 \\
\mathrm{~F} 1=\mathrm{F} 2=F \\
\Delta \mathrm{gap}=(F 1 L 1 / E 1 A 1)+(F 2 L 2 / E 2 A 2) \\
F=(\Delta \operatorname{gap} /(L 1 / E 1 A 1+L 2 / E 2 A 2))
\end{gathered}
$$

The forces occurring in the truss members are given analytically as presented below: Eq. (7 and 8).

Where F, E, A and $\Delta$ are the force exerted on the member, the modulus of elasticity, the cross-sectional area and the amount of the imperfection of the member, respectively. The problem explained above has been solved by the computer program prepared in this study. The results are compared in Table 1. As clearly seen in Table 1 that numerically equivalent results with exact solution are obtained.

Table 1. The double-component system analyzed by considering the defects in components.

\begin{tabular}{|c|c|c|c|c|}
\hline \multirow{2}{*}{ Component No } & \multicolumn{2}{|c|}{ F (KN) } & \multicolumn{2}{|c|}{$\boldsymbol{\mathbf { 2 }}(\mathbf{m m})$} \\
\cline { 2 - 5 } & $\mathbf{1}$ & 1121.495 & $\mathbf{2}$ & 37.38 \\
\hline Analytical solution & 1121.495 & 1121.495 & 37.38 \\
\hline Computer Program & 1121.495 & 37.38 & 37.38 \\
\hline
\end{tabular}

\subsubsection{El Sheikh's Approach to Model for Geometric Imperfections}

In this section, modeling of length imperfection used in the current study and the approach used in some of the previous papers by other researchers are compared. In some of the previous studies which investigate the effect of length imperfections was modelled through the use of El Sheikh's approach.

In El Sheikh's approach, two-step analyses are required. Firstly, the force required to stretch or shorten a disconnected imperfect member for fitting into ideal geometry must be calculated. Then a pair of loads, which are equal to the loads calculated from the first step, is applied along the members' longitudinal direction to the joints where the imperfect members are connected. Superposition of these two steps results in stress due to length imperfection in the distorted DLGST.

The approach used to consider length imperfection by El Sheik's Technique needs two step analyses (superposition) as explained above. In this method, material properties of the imperfect members are changed by considering length imperfection. El Sheik used commercial computer program in his analyses for length imperfections. These approaches require manual implementation due to the commercial software usage. This process is cumbersome and time consuming (Fig. 3)

The mentioned approach is not suitable for random assignment if there are so many imperfect members. Therefore, it is necessary to write a special computer program to overcome the above mentioned obstacles. The problem shown in Fig. (2) has been solved by El Sheik's Technique and the solution is given below in Eq. (11). 


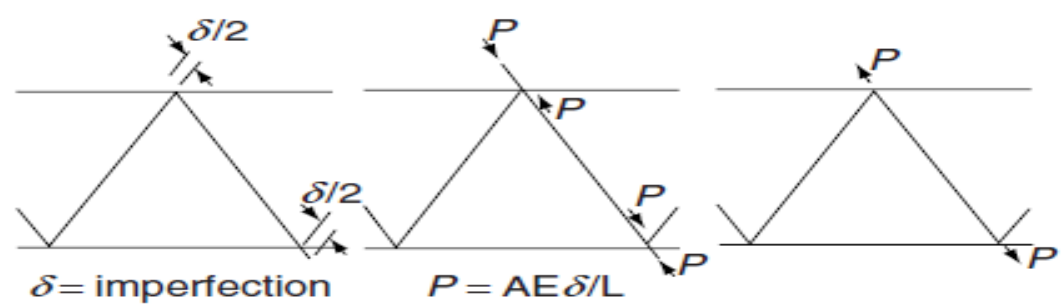

(a) Long member
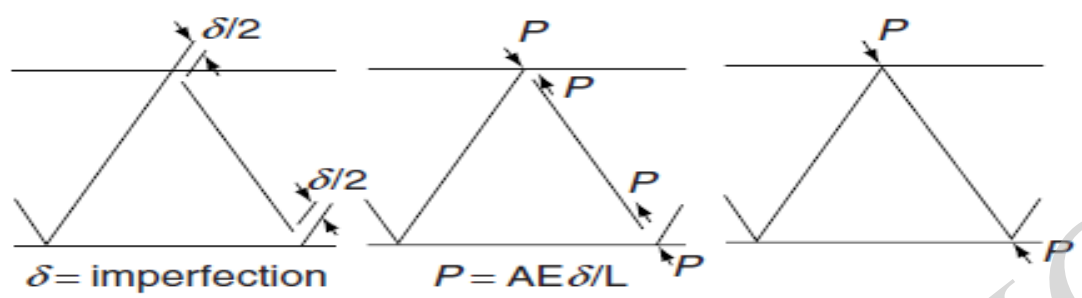

(b) Short member

Fig. (3). Modeling procedure of the imperfect members by El Sheikh's

$$
F=\frac{\Delta g a p}{\left(\frac{L 1}{E 1 A 1}+\frac{L 2}{E 2 A 2}\right)} * \frac{L_{2}}{L_{20}}
$$

The problem was solved earlier and the solution is given in Eq. (9). In El Sheikh's approach, as observed from Eq. (10), it is assumed that the lengths of perfect and imperfect members are equal. This assumption gives good results when the imperfection is too small. Otherwise, error increases as the imperfection increases. The problem used for the verification of the proposed program was solved with the El Sheikh approach too and the results are shown in Fig. (2). Comparison of the analytical and El-Sheikh solution is shown in Table 2. As shown in Table 2, El-Sheikhs' solution gives $8 \%$ error when compared with the analytical solution for the specific example.

Table 2. Comparison of Analytical and El Sheikh solution.

\begin{tabular}{|c|c|c|c|c|}
\hline \multirow{2}{*}{ Member No. } & \multicolumn{2}{|c|}{ F (KN) } & \multicolumn{2}{|c|}{$\boldsymbol{\Delta}(\mathbf{m m})$} \\
\cline { 2 - 6 } & $\mathbf{1}$ & $\mathbf{2}$ & $\mathbf{1}$ & $\mathbf{2}$ \\
\hline Analytical solution & 1121.495 & 1121.495 & 47.38 & 37.38 \\
\hline Ell Sheikh Approach & 1112.121 & 1112.121 & 40.40 & 40.40 \\
\hline Difference $\%$ & 8.08 & 8.08 & 8.08 & 8.08 \\
\hline
\end{tabular}

\subsection{Analytical Model}

\subsubsection{Numerical Simulation Procedure Verification of the Computer Program}

In this paper, a $10 \times 10$ bay offset double-layer grid structure has been studied. The plan dimensions of the lower layer and the upper layer are $30 \times 30$ and $27 \times 27$ square meters, respectively and the grid depth has been considered 1.5 meters. Each structure is composed of 512 members. The supports have been considered in the corners and assumed hinged as shown in Fig. (4). All members are assumed to be steel pipes and the material's yield stress, ultimate stress, and elasticity modulus have been considered as $240 \mathrm{MPa}, 360 \mathrm{MPa}$ and $210000 \mathrm{Mpa}$, respectively.

The design of the structure has been done under two different types of loads. The dead load which is equal to 0.5 $\mathrm{KN} / \mathrm{m}^{2}$, consists of the load of the covering and the joints. And the snow load which is equal to $2.0 \mathrm{KN} / \mathrm{m}^{2}$. In this model, the dead loads and the snow load have been exerted on the joints of the upper layer as concentrated loads, proportionate to the load bearing area of each joint. As an exception, the four diagonal members over the support nodes are considered to be solid bars so that the local collapse of these members and the instability of the entire structure will be prevented. 
The structure has been designed using AISC allowable stress design method and to achieve minimum structural weight it was observed that compression is the dominant response of the system. The design is based on optimizations according to the item of the weight, five sections with specified characteristics in Table 1, are used [25].

The DLGST structure was designed by using Allowable Stress Design (ASD) method. The cross-sectional design has been made according to the member, which received the biggest stress among the other members in each group (Lower, Upper, and Diagonal). All the members used in the model are steel pipes and material's yield strength and elastic modulus are $240 \mathrm{MPa}$ and $200 \mathrm{GPa}$, respectively. The geometric sectional properties obtained from the design are given in Table 3 .

Table 3. Member size of model grid structure.

\begin{tabular}{|c|c|c|c|c|c|}
\hline \multirow{2}{*}{ - } & \multicolumn{2}{|c|}{ Section Pipe } & \multirow{2}{*}{ Area $\left(\mathrm{mm}^{2}\right)$} & \multirow{2}{*}{$\begin{array}{c}\mathbf{L} \\
(\mathbf{c m})\end{array}$} & \multirow[b]{2}{*}{ 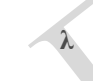 } \\
\hline & $\mathrm{d}(\mathrm{mm})$ & $t(\mathrm{~mm})$ & & & \\
\hline Lower Bar & 180 & 8 & 4322 & 400 & 65.7 \\
\hline Upper Bar & 220 & 8 & 5328 & 400 & 53 \\
\hline Diagonal & 160 & 7 & 3364 & 4272 & 78.9 \\
\hline
\end{tabular}

The initial geometrical imperfection has been considered as a sinusoidal half-wave in such a way that the maximum deviance will be in the mid-span of the member Fig. (5). This member was created in SeismoStruct Software with twenty Elastic-Perfectly Plastic non-linear displacement-based beam-column elements with equal length, integrated at 4 points along the element. The integration is based on the Gauss-Legendre quadrature rule which enforces Bernoulli beam assumptions. All the subjected profiles in this study have been modeled using the "Fiber section" model in the SeismoStruct software. The cross section of the member along its radius and circumference has been divided into 4 and 16 equal parts, respectively Fig. (5). Finally, the axial force-displacement relationship of the model was obtained through displacement control analysis using arc length algorithm considering both geometric and material non-linearity.

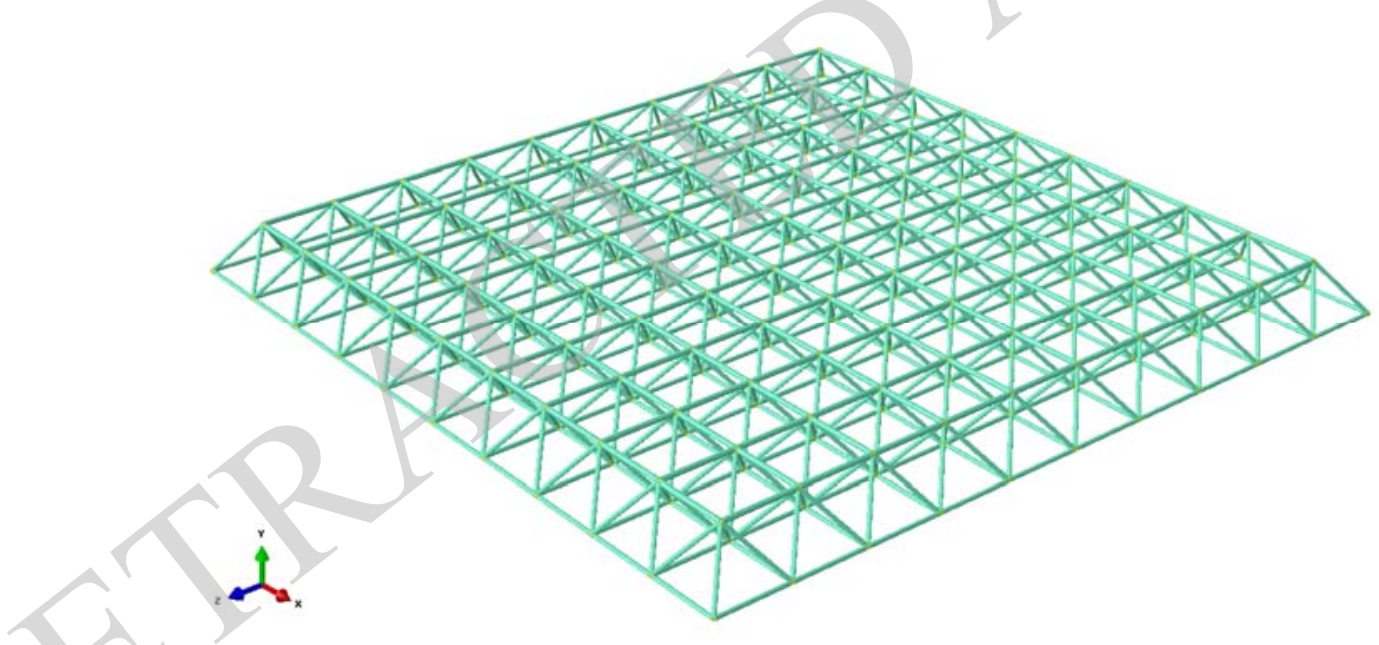

Fig. (4). General view of the model formed with DGS.
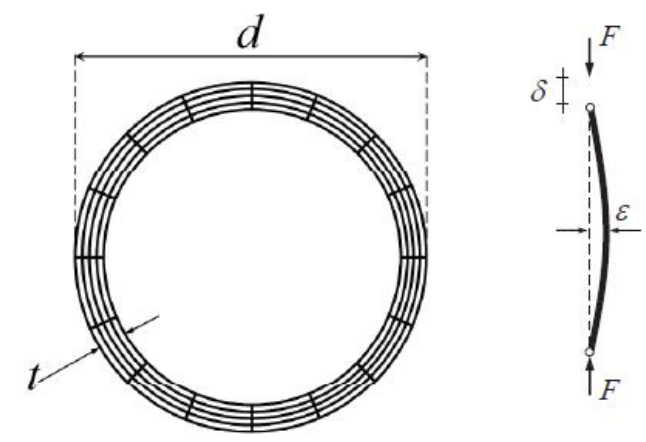

Fig. (5). Geometrical and meshing specifications of the compression member model.

Most critical member is defined as the member, which takes maximum stress among others. Fig. (6) shows the 
capacity ratio of top members of the truss. The capacity ratio is defined as the ratio of stresses on a member to allowable stress of the member. In this Fig. (6) x-axis shows the truss members and $y$-axis shows the capacity ratio of the members. As seen from Fig. (6), all the member capacity ratios are less than the limit capacity ratio of 1 , which is considered as safe design. As it is obvious from Fig. (6), there are few members whose capacity ratios are around 0.8 . The capacity ratios of more than half of the members are less than 0.5 .

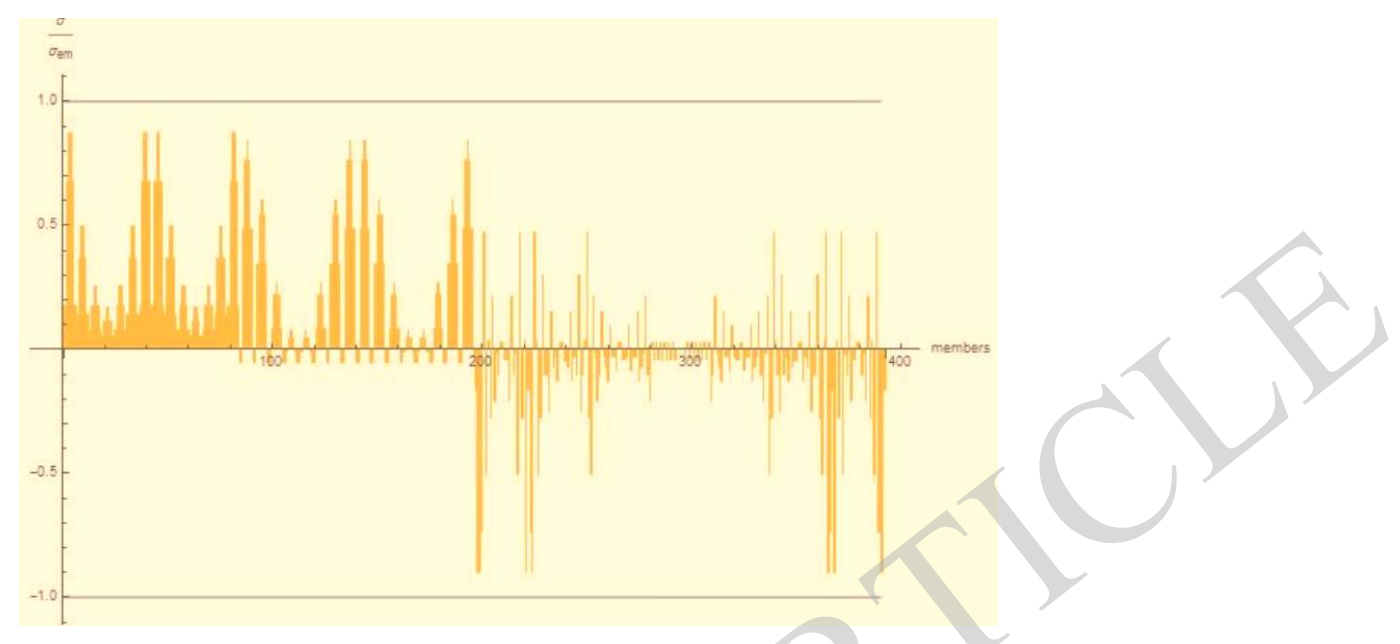

Fig. (6). The Capacity Ratio of top members of Perfect DLGST (No length imperfections, perfect member).

\section{RESULTS OF ANALYSES DLG SPACE TRUSS WITH LENGTH IMPERFECTIONS}

In this section, results of the numerical analyses on the DLGST are presented. Using the DLGST, so many cases involving changes of the parameters defined above were considered and behavior in each case was compared with that of the perfect DLGST model. Perfect DLGST is defined as the truss with no imperfect members, which was analyzed in section 3.1 .

In this part of the study, the DLGST model which was designed according to the perfect member lengths has been analyzed by considering imperfections in member length. The size of length imperfections $(\Delta \mathrm{L})$ and the number of the imperfect members are defined as the inputs of the developed program. The program assigns the position of imperfect members randomly.

Performance of structures and comparisons between DLGST models were made based on members' capacity ratios, the total energy of the structure, and a number of over stress members. Total energy of a truss and capacity ratio is defined as below, respectively in Eq. (12 and 13).

$$
\begin{gathered}
U=\sum_{i=1}^{n} \int_{0}^{L} \sigma_{i} * \frac{\varepsilon}{E} d x \\
\text { Capacity ratio }=\frac{\sigma_{i}}{\sigma_{\text {allwable }}}
\end{gathered}
$$

\subsection{Size of Length Imperfection Effect}

To investigate the effect of length imperfections' size $(\Delta \mathrm{L})$ on DLGST behavior, several cases with different sizes of length imperfections were analyzed by keeping the number of imperfect members and position of imperfect members constant.

The DLGST model in Fig. (3) has been reanalyzed for $5 \mathrm{~mm}$ and $10 \mathrm{~mm}$ length imperfections separately, while keeping 110 imperfect members and position of imperfect members constant. In the present study on DLGST, 110 different members were assumed to have length imperfections. The issue of whether imperfect member being too short or too long is defined by the program randomly. Fig. (7) shows the position of imperfect members which are assigned by the computer program. The red bars show the members that are shorter than the ideal size, whereas the purple bars show the members that are longer than the ideal size. 


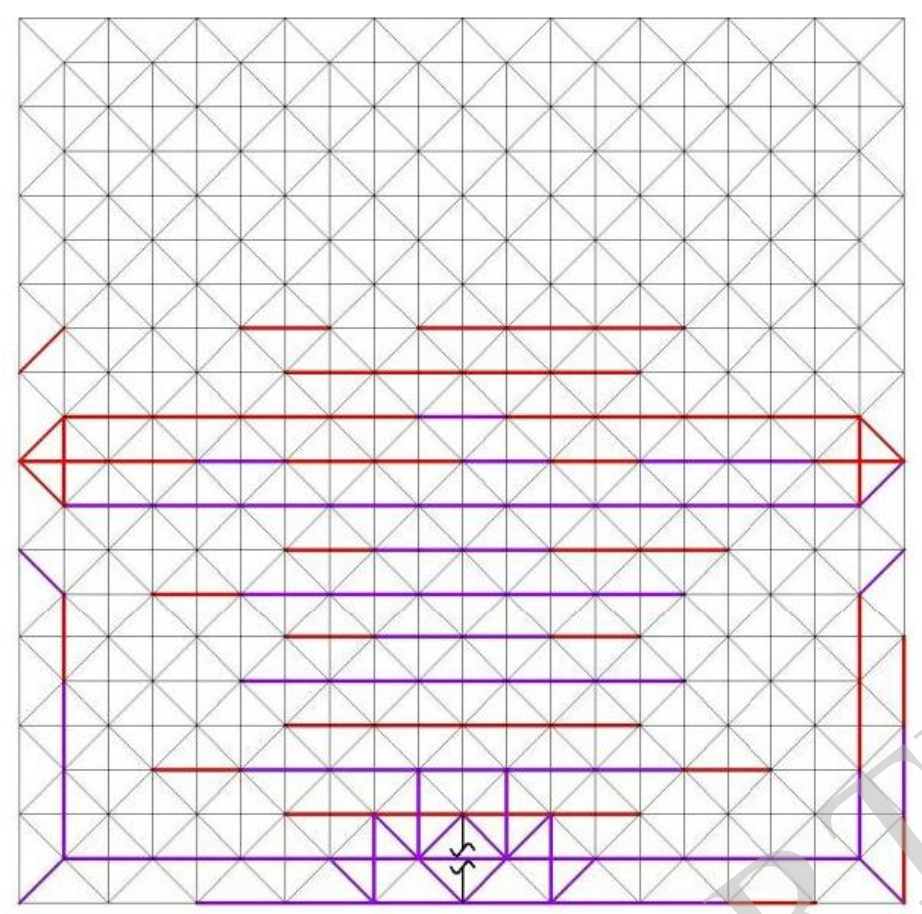

Fig. (7). Position of defined 110 imperfect members.

It is seen that some of the members exceed the limit capacity ratio in the DLGST models (Figs. 8 and 9). The red parts in Figs. (8 and 9) show the components that have reached their capacities due to compression, whereas the green bars show the members that have reached their capacities due to tension. As seen from these figures, higher the length of imperfection, more the number over stress members.

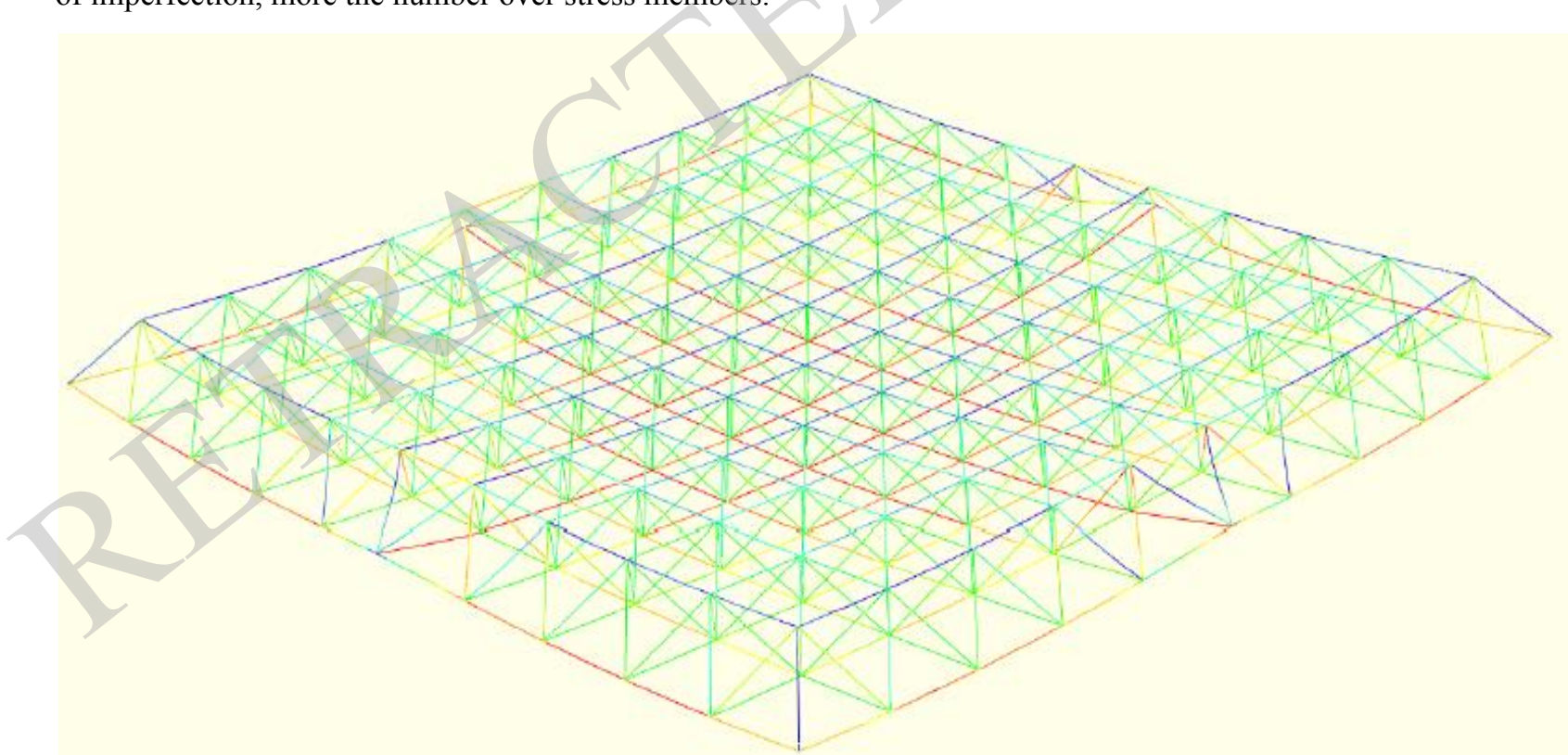

Fig. (8). Deform shape of DLST after $5 \mathrm{~mm}$ length imperfection assign to the members shown in (Fig. 7) . 


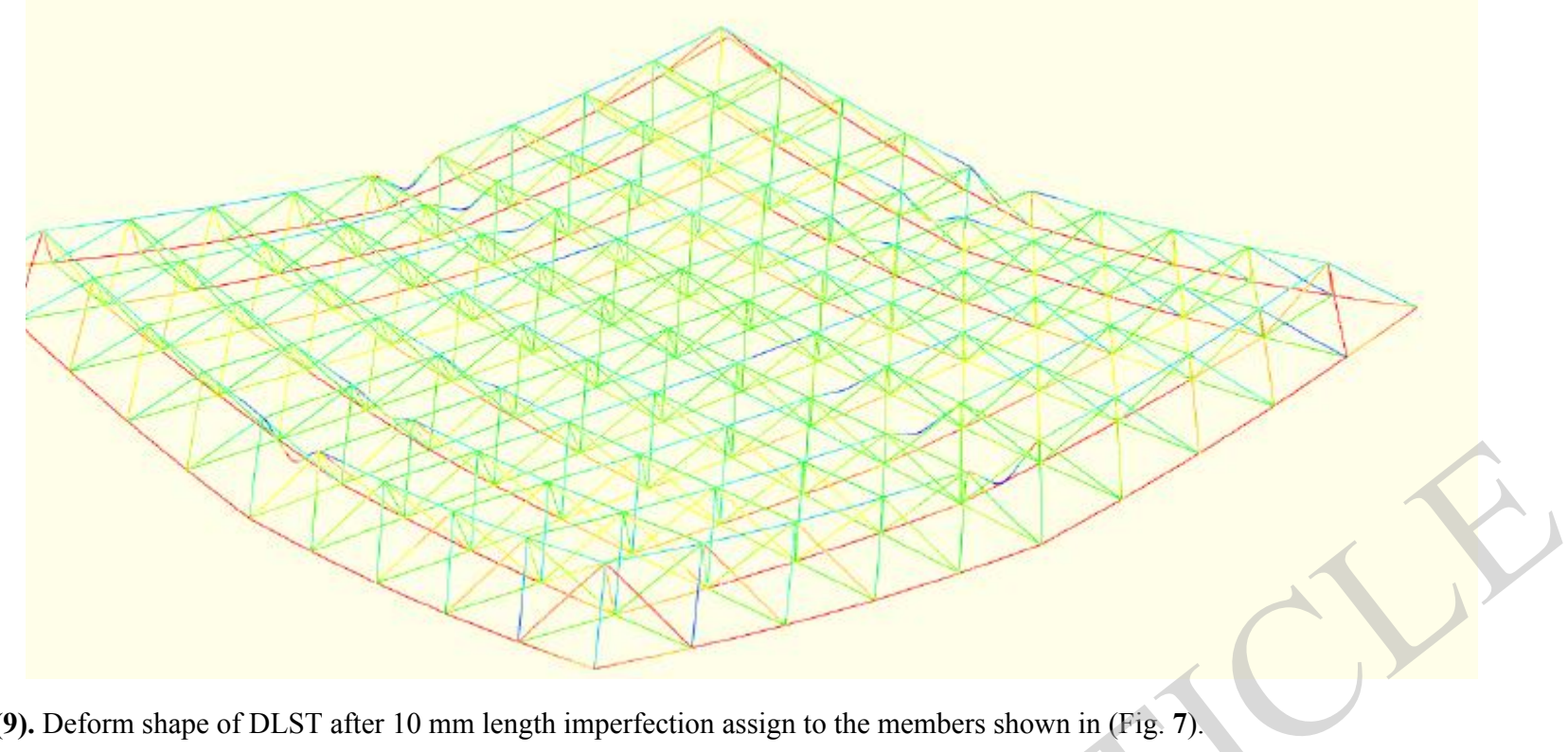

Fig. (9). Deform shape of DLST after $10 \mathrm{~mm}$ length imperfection assign to the members shown in (Fig. 7).

Figs. (8 and 9) show the comparison of capacity ratio of members for DLGST with perfect members and DLGST with the size of length imperfection of $5 \mathrm{~mm}$ and $10 \mathrm{~mm}$, respectively. While the left parts of the figures show the results obtained from the perfect member, the right parts of the figures show the results obtained from DLGST with length imperfections. In these figures, $\mathrm{x}$-axis shows capacity ratio, and $\mathrm{y}$-axis shows member name. Table 4 shows comparisons between DLGST with imperfect members and DLGST with perfect members. Table $\mathbf{4}$ contains total energy of the trusses and number of over stress members. As seen from the Figs. (10 and 11) and the Table 4, the size of imperfection length increases the capacity ratio of the members. Some of the member's capacity ratio in DLGST exceeds 1.

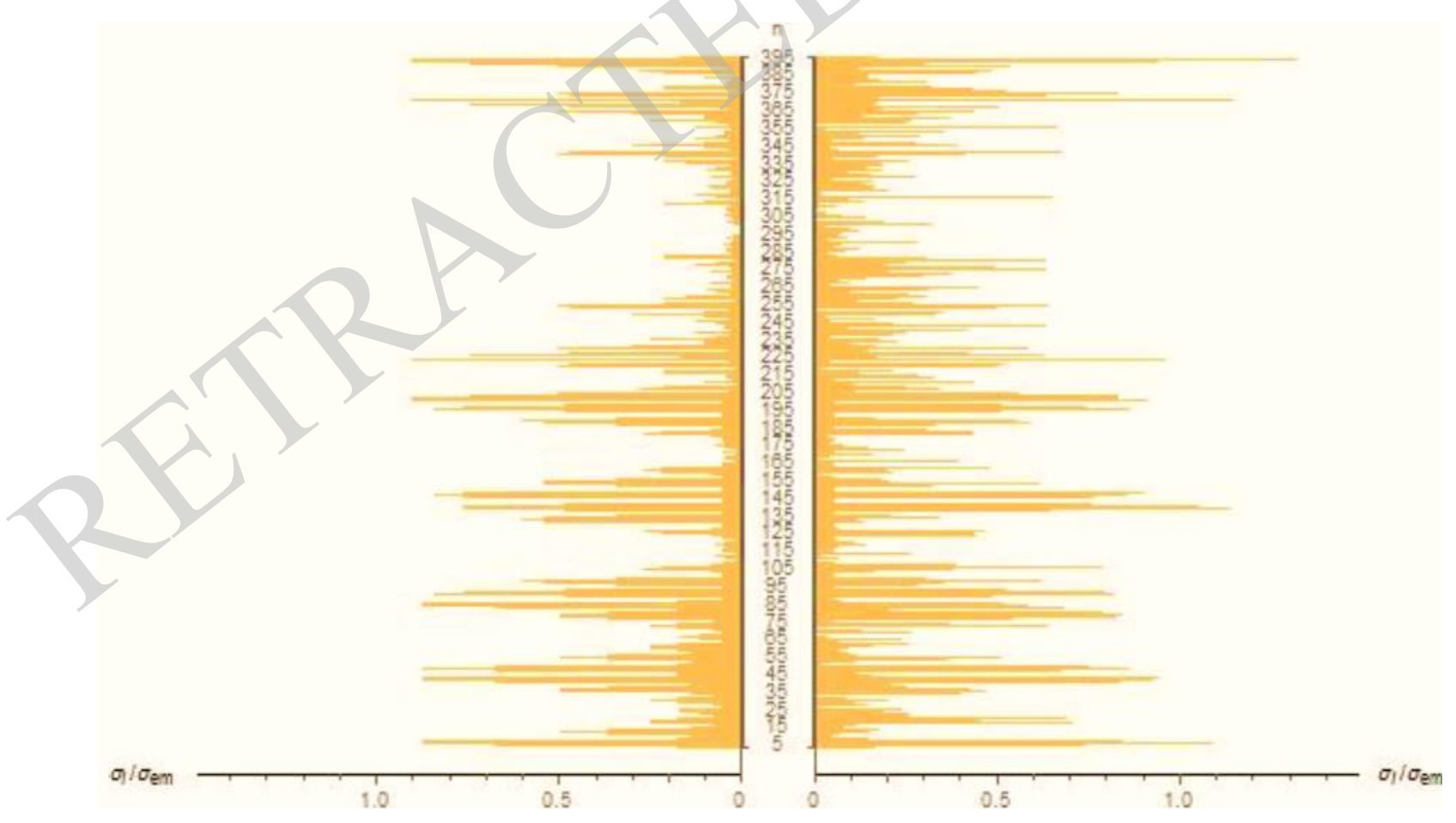

Fig. (10). shows comparison of capacity ratio of members between perfect truss and imperfect truss considering $\Delta \mathrm{L}=5 \mathrm{~mm}$. 


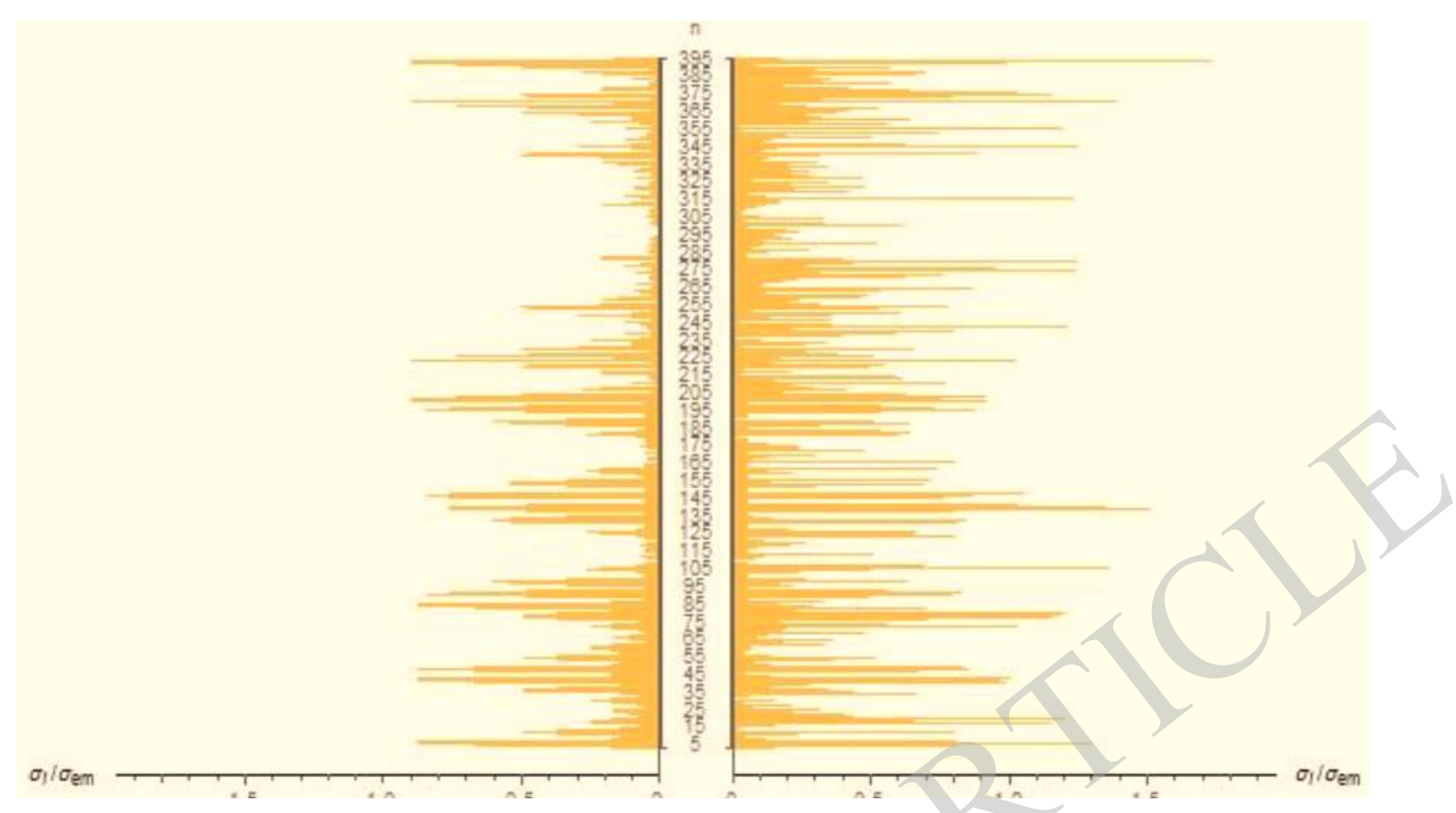

Fig. (11). shows comparison of capacity ratio of members between perfect truss and imperfect truss considering $\Delta \mathrm{L}=10 \mathrm{~mm}$.

Table 4. Comparison different size of length imperfections.

\begin{tabular}{|c|c|c|c|}
\hline \multirow{2}{*}{-} & Case 1 & Case 2 & Case 3 \\
\cline { 2 - 4 } & Perfect Truss & $\begin{array}{c}\text { Imperfect Truss } \\
\mathbf{d L}=\mathbf{5 m m}\end{array}$ & $\begin{array}{c}\text { Imperfect Truss } \\
\mathbf{d L}=\mathbf{1 0} \mathbf{m m}\end{array}$ \\
\hline Total Energy (KJ) & 27.29 & 35.61 & 60.547 \\
\hline Number of over stress members & 0 & 7 & 31 \\
\hline
\end{tabular}

\subsection{Position of Imperfect Members}

To investigate the effect of position of length imperfections on DLGST behavior, 500 cases with different positions of imperfect members were analyzed by keeping number of imperfect members and size of length imperfections constant. The computer program selects the member to be assigned imperfections randomly. A number of over stress members and total energy of trusses were calculated for every set of random position of imperfect members. In practice, the possibility of a situation violates the design rules can be obtained from the histogram graphs. Fig. (10) shows the number of overstress member histogram. In this figure, $\mathrm{x}$-axis shows the number of over stress members, $\mathrm{y}$-axis shows the number of cases among the 500 analyses corresponding to the $\mathrm{x}$-axis.

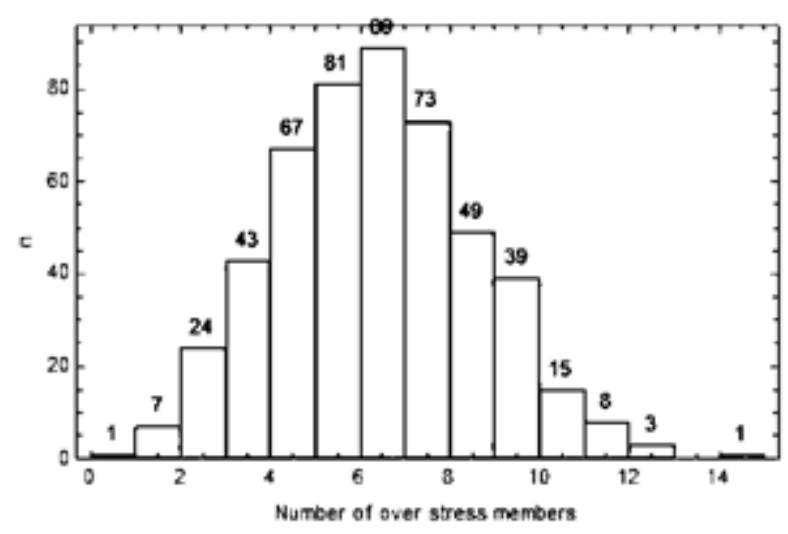

Fig. (12). Histogram of number of over stress members. 
Fig. (12) shows histogram of total strain energy of the trusses. As seen from the Figs. (12 and 13), the positions of the imperfect members affect the DLGST behavior. These show that the response of DLGST is probabilistic, even if some of the uncertainties (number of imperfect members, size of length imperfection) are kept constant. These Figures show that the selection of imperfect member has a remarkable effect on the structure safety.

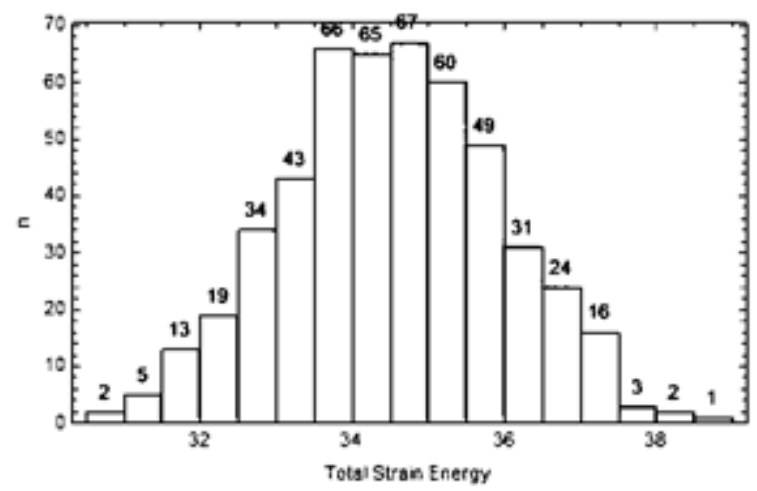

Fig. (13). Histogram of number of total strain energy.

As seen from Figs. (12 and 13), the position of the imperfect members has an effect on the structural behavior. The program prepared in this work has the capability that can define most critical situations among the 500 run and can draw these DLGST with imperfect members as shown in Fig. (14). The figure shows imperfect member positions. These most critical situations might be helpful at the assembly stage to not to get imperfect member especially in this pattern as shown in (Fig. 14).
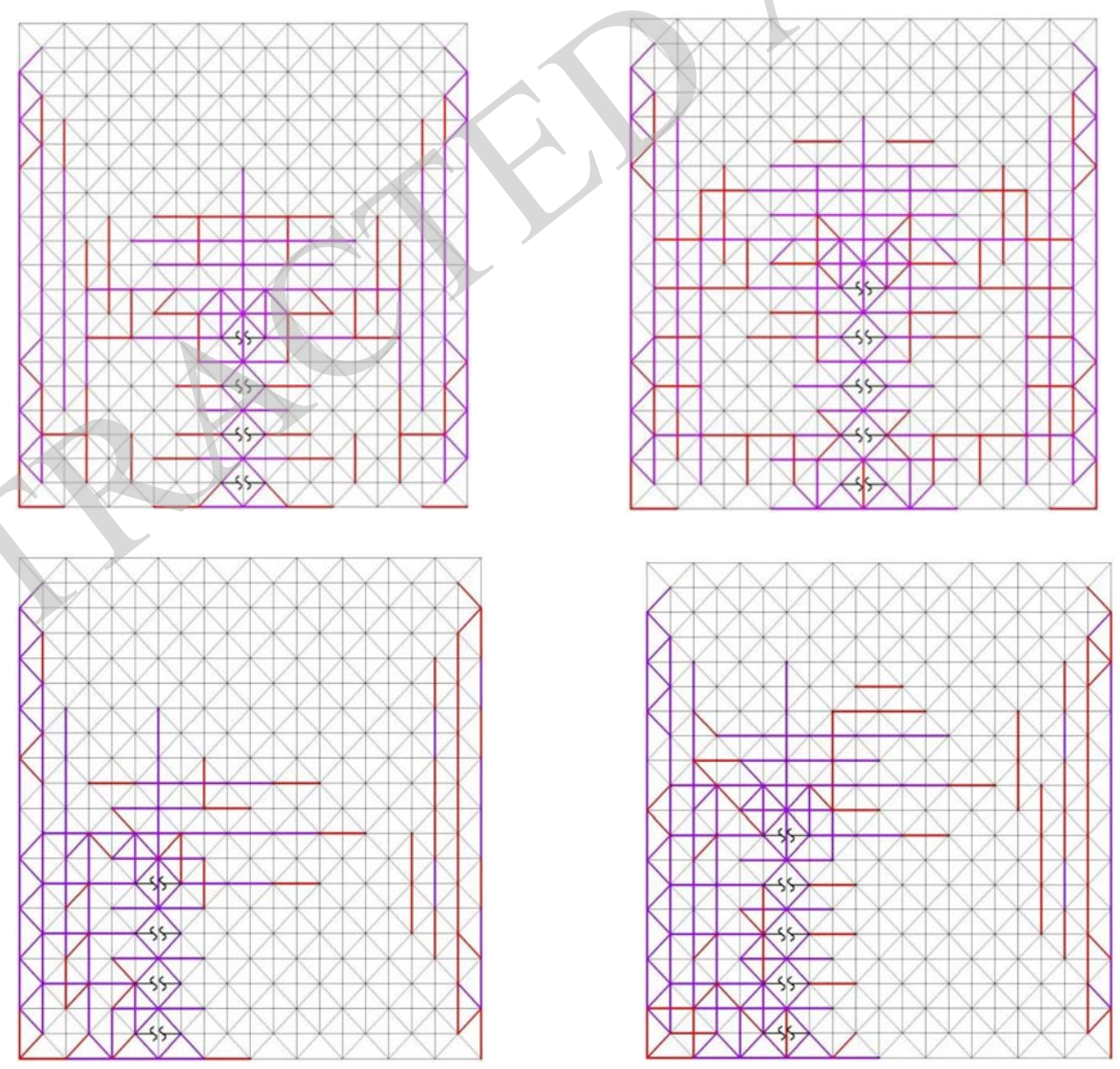

Fig. (14). Four most critical imperfect member position over 500 models. 


\section{RESULTS AND DISCUSSION}

The negative effect of small length imperfections on building safety is obvious as described in the analyses above. It is clear that the size of length imperfection of member and numbers of the imperfect members are main factors that affect the structural safety in a negative manner. Even in case the size of imperfections of member in its length $(\Delta \mathrm{L})$ and the number of the imperfect member is kept constant, the issue of which members to be assigned imperfections in their length also affects the results. In order to investigate the effect of the selection of imperfect members, the analyses were repeated under the same length imperfection $(\Delta \mathrm{L})$ and under the fixed number of imperfect members only by changing the members to be assigned with imperfections randomly. The analyses were repeated under these fixed values (length imperfection size $\Delta \mathrm{L}$ ) only by changing the components to be assigned with deficiencies for 500 times; and the number of the components which exceeded their capacity limit values are shown in histogram curve in Fig. (12).

It is shown that the size of imperfection in the length $(\Delta \mathrm{L})$ and the place of the imperfect members are important parameters influencing the behavior of the structure.

\section{CONCLUSION}

In this study, the sensitivity of the performance of the Double Layer Grid Space Trusses to manufacturing and assembly defects is explored. The program assigned the positions of imperfect members randomly by considering the magnitude of length imperfections $(\Delta \mathrm{L})$ members. The analyses have been done after assigning the length imperfections to the some members randomly. Some results of the present study are as follows:

- Analyses results have demonstrated that the observed knockdown in DLGST's performance due to imperfections is a consequence of the length imperfection. It is also shown that the performance of imperfect members depends upon the size of the length imperfections, number of imperfect members, and position of imperfect members.

- The critical members are located on the bottom layer in an area close to the supports and top layer in other areas.

- The collapse mechanism of the models is dependent on different parameters such as rise to span ratio, location of critical members, amount of post buckling stiffness of the members and also the amount of the distributed force after buckling of critical members.

- Conducted analyses on a selected offset double-layer grid structures by employing the simulation method indicate the high sensitivity of these structures to initial geometrical imperfections.

\section{FUNDING}

The author(s) received no financial support for the research, authorship, and/or publication of this article.

\section{CONSENT FOR PUBLICATION}

Not applicable.

\section{CONFLICT OF INTEREST}

The authors declare no conflict of interest, financial or otherwise.

\section{ACKNOWLEDGEMENTS}

Declared none.

\section{REFERENCES}

[1] R. Martin, and N.J. Delatte, "Another look at hartford civic center coliseum collapse", J. Perform. Constr. Facil., vol. 15, no. 1, pp. 31-36, 2001.

[http://dx.doi.org/10.1061/(ASCE)0887-3828(2001)15:1(31)]

[2] Z.S. Makowski, Analysis, design and construction of double-layer grids. Newyork: Halsted Press Division Wiley, 1981. 
[3] E. Murtha-Smith, "Alternate path analysis of space trusses for progressive collapse", J. Struct. Eng., vol. 114, no. 9, pp. 1978-1999, 1988. [http://dx.doi.org/10.1061/(ASCE)0733-9445(1988)114:9(1978)]

[4] G. Kaewkulchai, and E.B. Williamson, "Beam element formulation and solution procedure for dynamic progressive collapse analysis", Comput. Struc., vol. 82, no. 7-8, pp. 639-651, 2004.

[http://dx.doi.org/10.1016/j.compstruc.2003.12.001]

[5] A. Affan, and C. Calladine, "Initial bar tensions in pin-jointed assemblies", Int. J. Space Structures, vol. 4, no. 1, pp. 1-16, 1989. [http://dx.doi.org/10.1177/026635118900400101]

[6] A. Affan, and C.R. Calladine, "Structural mechanics of double-layer grids", in Shells, Membranes and Space Frames: Proceedings of the IASS Symposium on Membrane Structures and Space Frames, vol. 3, 1986 Elsevier, Osaka

[7] E.A. Smith, "Space truss nonlinear analysis", J. Struct. Eng., vol. 110, no. 4, pp. 688-705, 1984. [http://dx.doi.org/10.1061/(ASCE)0733-9445(1984)110:4(688)]

[8] E.A. Smith, and H.I. Epstein, "Hartford coliseum roof collapse: Structural collapse sequence and lessons learned", Civil Engineering-ASCE, vol. 50 , no. 4 , pp. $59-62,1980$.

[9] A. Hanaor, " Preliminary investigation of double-layer tensegrities", Proceedings of international conference on the design and construction of non-conventional structures, 1987. [http://dx.doi.org/10.4203/ccp.7.14.1]

[10] A. Hanaor, C. Marsh, and G.A. Parke, "Modification of behavior of double-layer grids: Overview", J. Struct. Eng., vol. 115, no. 5, pp. 1021-1037, 1989.

[http://dx.doi.org/10.1061/(ASCE)0733-9445(1989)115:5(1021)]

[11] A. Wada, and Z. Wang, "Influences of uncertainties on mechanical behavior of a double-layer space truss", Int. J. Space Structures, vol. 7, no. 3, pp. 223-235, 1992. [http://dx.doi.org/10.1177/026635119200700306]

[12] A. El-Sheikh, "Effect of member length imperfections on triple-layer space trusses", Eng. Struct., vol. 19, no. 7, pp. 540-550, 1997. [http://dx.doi.org/10.1016/S0141-0296(96)00120-4]

[13] A. Ei-Sheikh, "Sensitivity of space trusses to member geometric imperfections", Int. J. Space Structures, vol. 10, no. 2, pp. 89-98, 1995. [http://dx.doi.org/10.1177/026635119501000202]

[14] M.R. Sheidaii, and M. Gordini, "Effect of random distribution of member length imperfection on collapse behavior and reliability of flat double-layer grid space structures", Adv. Struct. Eng., vol. 18, no. 9, pp. 1475-1485, 2015. [http://dx.doi.org/10.1260/1369-4332.18.9.1475]

[15] M.T. Roudsari, and M. Gordini, "Random imperfection effect on reliability of space structures with different supports", Struct. Eng. Mech., vol. 55, no. 3, pp. 461-472, 2015.

[http://dx.doi.org/10.12989/sem.2015.55.3.461]

[16] M.R. Davoodi, "Determination of nonlinear behavior of a ball joint system by model updating", J. Construct. Steel Res., vol. 71, pp. 52-62, 2012. [http://dx.doi.org/10.1016/j.jcsr.2011.11.011]

[17] M. Gordini, " Reliability analysis of space structures using monte-carlo simulation method", In: Reliability Analysis of Space Structures Using Monte-Carlo Simulation Method. in Structures., 2018. Elsevier

[18] M. Gordini, "Reliability analysis of double-layer domes with stochastic geometric imperfections", Advance In comput. Des., vol. 2, no. 2, pp. 133-146, 2017. [http://dx.doi.org/10.12989/acd.2017.2.2.133]

[19] M.T. Roudsari, "Probability analysis of double layer barrel vaults considering the effect of initial curvature and length imperfections simultaneously", Int. J. Steel Struct., vol. 17, no. 3, pp. 939-948, 2017. [http://dx.doi.org/10.1007/s13296-017-9006-9]

[20] Z. Zhou, J. Wu, and S. Meng, "Influence of member geometric imperfection on geometrically nonlinear buckling and seismic performance of suspen-dome structures", Int. J. Struct. Stab. Dyn., vol. 14, no. 03, p. 1350070, 2014. [http://dx.doi.org/10.1142/S0219455413500703]

[21] M.A. Mousavi, K. Abedi, and M. Chenaghlou, "Imperfection sensitivity analysis of double domes free form space structures", Int. J. Struct. Stab. Dyn., vol. 15, no. 04, p. 1450067, 2015. [http://dx.doi.org/10.1142/S0219455414500679]

[22] H.T. Thai, and S.-E. Kim, "Large deflection inelastic analysis of space trusses using generalized displacement control method", J. Construct. Steel Res., vol. 65, no. 10-11, pp. 1987-1994, 2009. [http://dx.doi.org/10.1016/j.jcsr.2009.06.012]

[23] F. Trentadue, " Effect of initial imperfections on the buckling of space truss structures", Proceedings of the fourth international conference on space structures, , 1993 [http://dx.doi.org/10.1680/ss4v1.19683.0011]

[24] N.F. Morris, "Effect of imperfections on lattice shells", J. Struct. Eng., vol. 117, no. 6, pp. 1796-1814, 1991. 
[http://dx.doi.org/10.1061/(ASCE)0733-9445(1991)117:6(1796)]

[25] Construction, A.I.o.S., Seismic provisions for structural steel buildings. American Institute of Steel Construction, 2002.

\section{(C) 2018 Gordini et al.}

This is an open access article distributed under the terms of the Creative Commons Attribution 4.0 International Public License (CC-BY 4.0), a copy of which is available at: https://creativecommons.org/licenses/by/4.0/legalcode. This license permits unrestricted use, distribution, and reproduction in any medium, provided the original author and source are credited. 